\title{
Vocal conditioning in the guinea pig'
}

daVId D. BURNSTEIN ANo PETER C. WOLFF

STATE UNIVERSITY COLLEGE AT POTSDAM, NEW YORK

Two male guinea pigs were trained to vocalize for ICS reinforcement. Ss were differentially reinforced for calls in the 1000-2000 cps audio frequency range. When this vocal behavior was stabilized, reinforcement was made contingent on calls in the 2000-4000 cps range. Reinforcement of the 2000-4000 cps calls resulted in an increased proportion of calls in this range and a decreased proportion of calls in the 1000-2000 cps range. Sonograms of the calls under the two conditions showed the development of different sonic patterns.

Recent psychological studies have shown that mammals such as the rat (Sapon, 1965), guinea pig (Burnstein \& Wolff, 1965), cat (Molliver, 1963), dog (Salzinger \& Wallis, 1962), and dolphin (Lilly, 1962), could be conditioned to vocalize at higher than normal rates. The purpose of this study was to change the rate of emission of selected audio frequencies in the guinea pig call through differential reinforcement.

Two male albino guinea pigs, four months old and over $900 \mathrm{gm}$, were chronically implanted with stainless steel bipolar electrodes. Ss were allowed one week to recover from the operation. Ss were then placed in a standard operant conditioning chamber and trained to a bar in order to determine if the ICS was positively reinforcing and to specify the best stimulation parameters. Ss who responded on the bar to receive ICS were then moved to the vocal chamber, a 12 in. $x 12$ in. $x 16$ in. wooden box lined with foam rubber. A Grason-Stadler E7300A-2 microphone was housed in the ceiling of the chamber and fed into a pre-amp in the control room. From the pre-amp, calls went into a series of ban pass filters which analyzed the calls into frequency ranges of 1000$2000 \mathrm{cps}, 2000-4000 \mathrm{cps}$, and 4000-8000 cps. The filters were set to respond to a call rate as high as 190 calls per min. The intensity of the call needed to set off a filter remained constant across filters. Outputs from the filters operated standard control equipment, counters, and a strip chart recorder.

Since the Ss did not emit vocalizations when placed in the vocal chamber, a procedure similar to Salzinger (1962) was used. A second guinea pig was induced to vocalize in the presence of the experimental S. During the second guinea pig's vocalization, the experimental $S$ was reinforced on a low FR schedule. When the experimental $S$ began to vocalize, the second guinea pig was removed. Ss were then shaped to vocalize for ICS on either a FR5 or FR10 reinforcement schedule. Reinforcement was made contingent on vocallzations in the $1000-2000 \mathrm{cps}$ range.
A count was kept of vocalizations in the $2000-1000 \mathrm{cps}$ and 4000-8000 cps range.

After vocal behavior stabilized under the FR for the differentially reinforced $1000-2000$ cps range, the Ss were reinforced for vocalization in the 20004000 cps range. S-BP was reinforced on a FR5 for calls in the 1000-2000 cps range. When this behavior stabilized, $S$ was reinforced for calls in the 2000$4000 \mathrm{cps}$ range on the CFR schedule. After stability was reached in this range, S-BP was again reinforced for calls in the 1000-2000 cps range on a FR3 schedule. Sessions were held for $1 \mathrm{hr}$. every other day. Stimulation consisted of a 100-500 microampere pulse, 60 cycle ac of $0.3 \mathrm{sec}$. duration. Current was held constant for each $S$ during the experiment. Histological verification indicated that the electrodes were implanted in the supramammillary area.

\section{Results and Discussion}

Results for S-BP are shown in Fig. 1. The proportion of calls made in each frequency range is shown as a function of sessions and conditions. Proportion of calls were used since the proportions remained relatively constant regardless of the total vocal output. That is, whether the $S$ vocalized 2000 or 7000 times, the proportion of calls remained stable. As seen in Fig. 1, the proportion of calls made in the 1000-2000 cps decreased for S-BP when

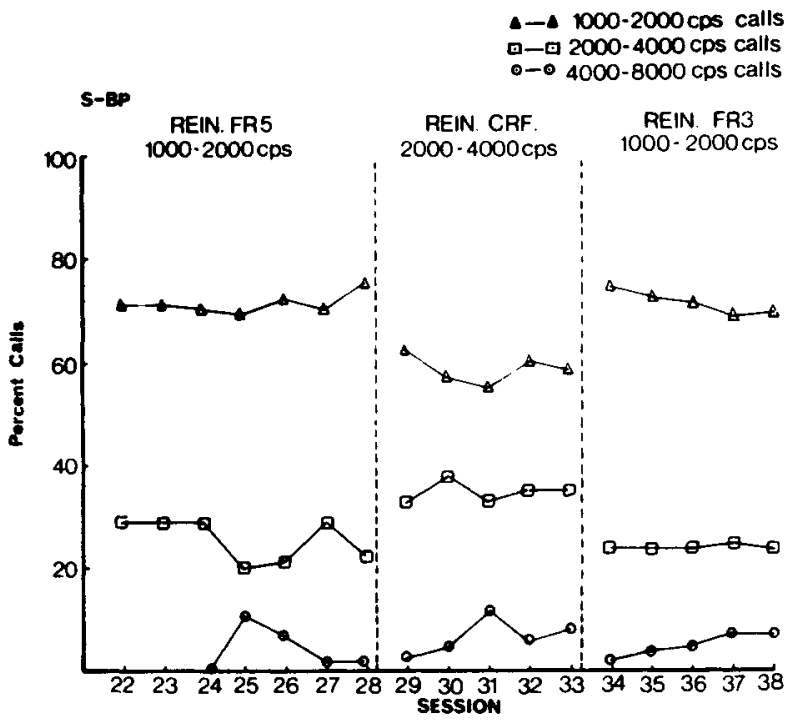

Fig. 1. Proportion of calls in the $1000-2000 \mathrm{cps}, 2000-4000 \mathrm{cps}$, and $4000-8000 \mathrm{cps}$ range for 3 conditions of differential reinforcement. SBP. 


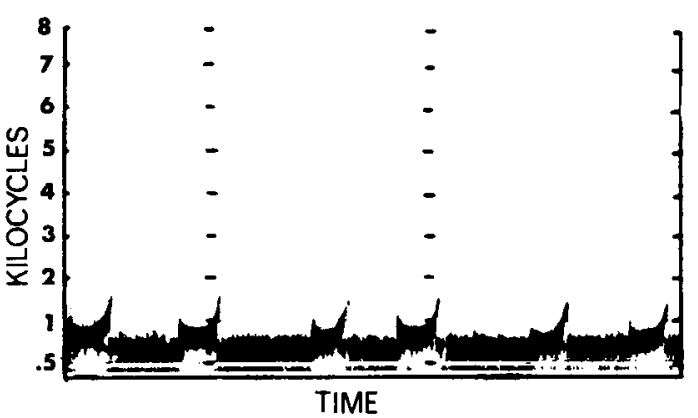

Fig. 2. Sonogram of a typical guinea pig call made under 1000$2000 \mathrm{cps}$ reinforcement condition. Audio frequency is shown as a function of time. Six calls are shown in 3 seconds.

reinforcement was made contingent on the 2000$4000 \mathrm{cps}$ call. The proportion of calls in the 20004000 cps range decreased when S-BP was taken back to the 1000-2000 cps schedule and as shown in Fig. 1, there was a decrease in $2000-4000 \mathrm{cps}$ calls and an increase in 1000-2000 cps calls. There was a decrease in the variability of the proportions in this replication. Calls in the 4000-8000 cps range for S-BP remained the same across all conditions. These results were systematically replicated with the second $\mathrm{S}$.

Figure 2 is a sonogram of typical calls made during the 1000-2000 cps reinforcement condition. The call

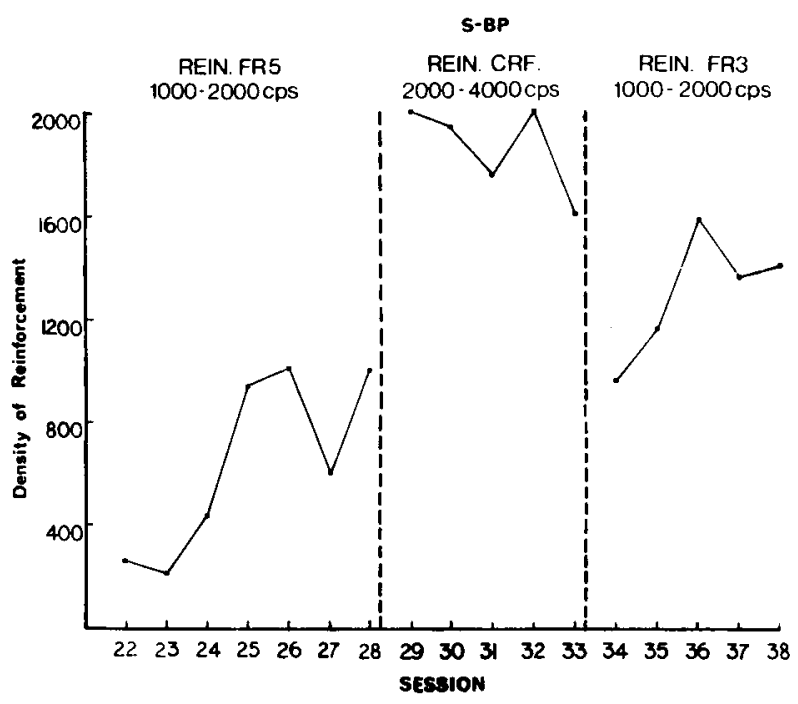

Fig. 4. The density of reinforcement for S-BP under the three differential reinforcement conditions.

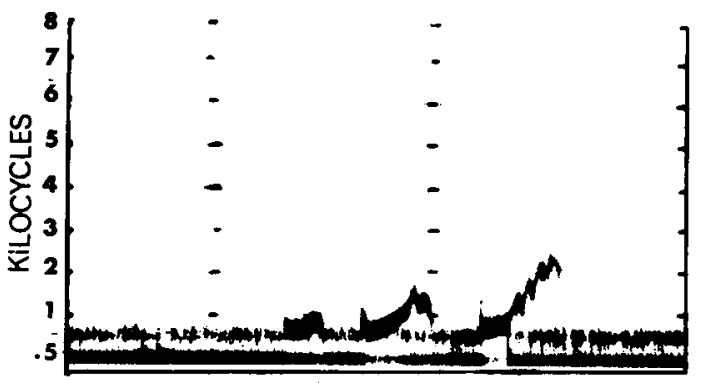

\section{TIME}

Fig. 3. Sonogram of the typical guinea pig call made under the 2000-4000 cps reinforcement condition. Audio frequency is shown as a function of time. Three calls are shown for the 2 second period.

began at a frequency of about $1000 \mathrm{cps}$, decreased to $750 \mathrm{cps}$ and then increased to over $1000 \mathrm{cps}$, but less than $2000 \mathrm{cps}$, and abruptly ended. Figure 2 shows six calls made in a period of $2 \mathrm{sec}$. Figure 3 is a sonogram of typical calls made during the 2000$4000 \mathrm{cps}$ reinforcement condition. As can be seen from this figure, the initial part of the call is similar to those calls in Fig. 2. Rather than ending abruptly, there was the development of a tail on the second and third call. The tail on the third call reached a frequency of over $2000 \mathrm{cps}$.

As can be noted from Fig. 1, the reinforcement schedules varied across the differentially reinforced conditions. Since the probability of a call in the 2000$4000 \mathrm{cps}$ range was low, it was necessary to decrease the FR requirements under the 2000-4000 cps reinforcement in order to prevent extinction of the vocal responses. Figure 4 shows the reinforcement density for S-BP. As can be seen from this figure, the reinforcement density differs in all three conditions. Figure 1 indicates that the proportion of calls under the FR5 and FR3, 1000-2000 cps reinforcement condition remains the same.

\section{References}

Burnstein, D. D., \& Wolf, P. C. Complex behavior repertoires through intracranial stimulation. American Psychological Association Meeting, September 1965.

Lilly, J. C., \& Miller, A. M. Operant conditioning of the Bottlenose Dolphin with electrical stimulation of the brain. J. comp. physiol. Psychol., 1962, 55, 73-80.

Molliver, Mark E. Operant control of vocal behavior in the cat. J. exp. Anal. Behav., 1963, 6, 197-202.

Salzinger, Kurt, \& Wallis, M. B. The operant control of vocalization in the dog. J. exp. Anal. Behav., 1962, 5, 383-389.

Sapon, S. M. Conditioning a vocal operant in a new laboratory rat. American Psychological Meetings, 1965. 